\title{
Pharmacokinetic of Flunixin Meglumine in Broiler Chicks by Enzyme-linked Immunosorbent Assay
}

\author{
Zahraa Alhumdany*', Yasser Albadrany \\ Department of Physiology, Biochemistry and Pharmacology, College of Veterinary Medicine, University of Mosul, \\ Mosul, Iraq \\ "Corresponding author. Email: zahraa.m.alhmdany@gmail.com
}

\begin{abstract}
Objective: The aim of the study was to investigate the concentration of flunixin in the plasma of chicks to determine the pharmacokinetic parameters.

Methods: A randomized controlled study was performed on forty five clinically healthy ross chicks of seven days old, chicks were administered into the peritoneum with a single dose of flunixin $18 \mathrm{mg} / \mathrm{kg}$ b.wt, following injection of the drug, blood samples were collected at $0,0.08,0.15,0.5,1,2,4,8,24 \mathrm{~h}$ (five chicks per time) from the jugular vein after decapitation. Then the plasma was obtained, the concentrations of flunixin in plasma samples were determined utilizing Enzyme-Linked Immunosorbent Assay, the pharmacokinetic parameters were calculated by the PKSolver program. Time vs. concentration curve for flunixin was obtained from the program. The pharmacokinetic parameters were determined with non-compartmental models.

Results: The concentration of flunixin in the plasma of chicks treated with flunixin by injection into the peritoneum at a dose $(18 \mathrm{mg} / \mathrm{kg})$ were $111.64 \pm 1.8,147.05 \pm 1.4,154.23 \pm 1.3,141,12 \pm 1.0,136.70 \pm 1.2,134.11 \pm 0.6,125.76$ $\pm 1.9,87$, and $76 \pm 1.5 \mu \mathrm{g} / \mathrm{ml}$ at times $0.08,0.25,0.5,1,2,4,8$ and 24 hours respectively. The maximum plasma concentration was $154.23 \mu \mathrm{g} / \mathrm{ml}$ during a period of 0.5 hour of treatment. The terminal elimination half-life was 31 hours, the terminal phase elimination rate constant was $0.021 \mathrm{~h}^{-1}$, the mean residence time was $45 \mathrm{~h}$, and the area under the curve from time 0 to infinity was $6733.27 \mu \mathrm{g} . \mathrm{h} / \mathrm{ml}$.

Conclusions: Based on the results of the study, we conclude the long elimination half-life of flunixin and the poor clearance from the animal body, which is reflected in the long effects of its analgesic, anti-inflammatory and antipyretic properties
\end{abstract}

Keywords: Flunixin meglumine, Pharmacokinetic, ELISA, Chicks.

\section{INTRODUCTION}

Chickens have been utilized as a study model widely throughout the history of biology; chicks have been used as a model for analgesia, anesthetic, and toxicity studies[1] Pharmacokinetics and pharmacodynamics of analgesic drugs in birds are poorly understood, making pain relief challenging in birds. Analgesic drugs combined with good care and management can help birds as well as mammals cope with stressful and painful situations [2].

Flunixin meglumine is a nonsteroidal anti-inflammatory medication (NSAID) that is extensively used in veterinary medicine as an analgesic, antipyretic, and anti-inflammatory treatment. It works by blocking the enzyme cyclooxygenase (COX), COX is involved in the arachidonic acid cascade, converting it to prostaglandins, by inhibiting COX, flunixin prevents the synthesis of prostaglandins and inflammatory mediators[3].

The objective of this study was to determine the pharmacokinetic properties of flunixin meglumine in healthy broiler chicks. 


\section{MATERIALS AND METHODS}

\subsection{Chemicals}

Flunixin meglumine $(50 \mathrm{mg} / \mathrm{ml}$, UVEDCO CO., JORDAN) was extra diluted in saline solution (Pioneer Company for Pharmaceutical Industries, IRAQ) to gain the necessary drug concentrations for injection. The volume of drug administration was $5 \mathrm{ml} / \mathrm{kg}$ body weight given intraperitoneally (i.p.).

ELISA kits for flunixin meglumine were from SigmaAldrich (St. Louis, MO, USA). All other reagents were of analytical grade and were commercially available.

\subsection{Animals}

This study was approved by the scientific board of the department of physiology, biochemistry and pharmacology of the college of veterinary medicine, university of Mosul. A randomized controlled study was performed on forty five clinically healthy Ross chicks of seven days of age weighting about 150 to $200 \mathrm{gm}$ were used in study. The animals were kept in a group inside cages prepared for breeding poultry in the animal's house of the Mosul veterinary college, covering the floor with sawdust, continuous lighting, with the availability of feed and water ad-libitum.

\subsection{Experimental design}

Forty- five healthy chicks were administered into the peritoneum with a single dose of flunixin $18 \mathrm{mg} / \mathrm{kg}$ b.wt[4]. Following injection of the drug, blood samples were collected at $0,0.08,0.15,0.5,1,2,4,8,24 \mathrm{~h}(5$ chicks per time). Blood was taken from the jugular vein after decapitation. Blood samples were collected in EDTA tubes.

\subsection{Sample Processing}

For each sampling time point, blood samples were stored on ice and were then centrifuged for 15 minutes at 3000 r.p.m. Plasma samples were kept frozen $(-20 \circ \mathrm{C})$ until analyzed.

\subsection{Determination of flunixin in plasma}

Concentrations of flunixin in plasma samples were determined utilizing Enzyme-Linked Immunosorbent Assay and the assay protocol according to the manufacturer's instructions as follow,

Bring all reagents to room temperature prior to use.

The expected concentration is unknown, a preliminary experiment is recommended to determine the sample dilutions and adjustments to the reaction time are required to bring the measured concentrations within the detection range of the kit.

1. Set the sample, standard and blank wells on the 96well microplate and record their positions. We recommend setting up each standard and sample in duplicate.

2. Add $50 \mu \mathrm{l}$ of sample to the sample wells.

3. Add $10 \mu \mathrm{l}$ of prepared standards to the standard first 4 wells.

4. Add $10 \mu \mathrm{l}$ of distilled water to the blank wells.

5. Add $50 \mu \mathrm{l}$ of Reaction Buffer (B) to each well.

6. Add $90 \mu \mathrm{l}$ of Reagent Solution (A) to each well.

7. Tap the plate gently to mix. Incubate at $50^{\circ} \mathrm{C}$ for 15 minutes in a convection oven.

10. Allow the plate to cool to room temperature, then read and record absorbance at $450 \mathrm{~nm}$.

Samples were diluted appropriately in dilution buffer containing $1 \%(\mathrm{w} / \mathrm{v})$ bovine serum albumin $\mathrm{BSA}$, and $0.05 \%$ Tween-20 in PBS. Flunixin calibration standards were prepared at the following concentrations: 62.5 , 125,250 , and $500 \mu \mathrm{g} / \mathrm{ml}$ in dilution buffer.

By using the equation of the simple linear regression of flunixin meglumine standards with a coefficient of determination $(\mathrm{R} 2=1)$, flunixin meglumine concentration in plasma samples can be calibrated and calculated in chicks (analyzed using Excel software 2010) were:

$\mathrm{y}=\mathrm{mx}+\mathrm{b}(\mathrm{y}=0.0848 \mathrm{x}+0)($ Equation of the simple linear regression of flunixin meglumine standards) (Figure 1)

$\mathrm{y}=$ flunixin meglumine absorbance in the plasma samples at $450 \mathrm{~nm}$

$\mathrm{b}=$ intercept

$\mathrm{m}=$ slope

$\mathrm{x}=$ unknown concentration of flunixin meglumine in the plasma samples.

\subsection{Pharmacokinetic calculations}

The pharmacokinetics parameters were calculated by PKSolver program[5]. Time vs. concentration curve for flunixin was obtained from the program. The pharmacokinetic parameters were determined with noncompartmental models. The main kinetic parameters obtained were Maximum plasma concentration( $C_{\max }$ ), Terminal Elimination Half-Life $\left(T_{1 / 2}\right)$, Time to Maximum Plasma Concentration $\left(T_{\max }\right)$, Terminal Phase Elimination Rate Constant $\left(\mathrm{K}_{\mathrm{e}}\right)$, Mean Residence Time (MRT), Area Under the Curve from time 0 to infinity $\left(\mathrm{AUC}_{0-\infty}\right)$. 


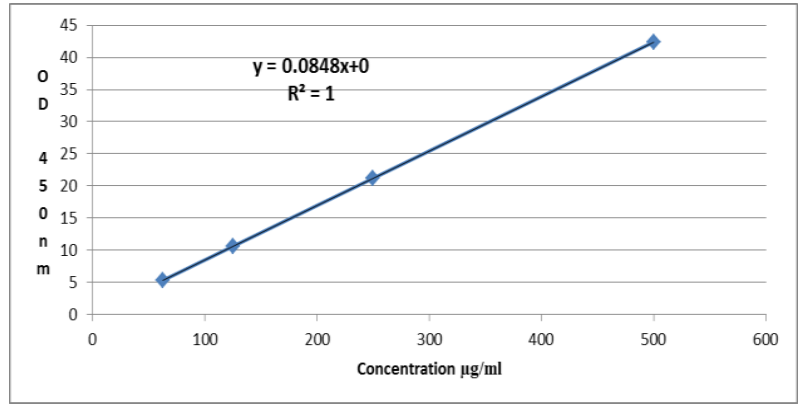

Figure 1 Calculation of the simple linear regression for flunixin meglumine standards $(62.5,125,250$, and 500 $\mu \mathrm{g} / \mathrm{ml})$, and their absorbance at $450 \mathrm{~nm}$.

\section{RESULTS}

\subsection{Flunixin concentration in the plasma of chicks.}

The concentration of flunixin in the plasma of chicks treated with flunixin through injection into the peritoneum at a dose $(18 \mathrm{mg} / \mathrm{kg})$ were $111.64 \pm 1.8$, $147.05 \pm 1.4,154.23 \pm 1.3,141,12 \pm 1.0,136.70 \pm 1.2$, $134.11 \pm 0.6,125.76 \pm 1.9,87$, and $76 \pm 1.5 \mu \mathrm{g} / \mathrm{ml}$ at times $0.08,0.25,0.5,1,2,4,8$ and 24 hours respectively (Table 1). Figure 2 shows the flunixin concentration with time, and the highest flunixin concentration was at 0.5 hour.

Table 1. Concentration of flunixin in the plasma of chicks treated with flunixin $(18 \mathrm{mg} / \mathrm{kg}$ b.wt, i.p) at different time.

\begin{tabular}{cc}
\hline Time $(\mathbf{h})$ & Concentration $(\boldsymbol{\mu g} / \mathbf{m l})$ \\
\hline 0.08 & $111.64 \pm 1.8$ \\
\hline 0.25 & $147.05 \pm 1.4$ \\
\hline 0.5 & $154.23 \pm 1.3$ \\
\hline 1 & $141.12 \pm 1.0$ \\
\hline 2 & $136.70 \pm 1.2$ \\
\hline 4 & $134.11 \pm 0.6$ \\
\hline 8 & $125.76 \pm 1.9$ \\
\hline 24 & $76.76 \pm 1.5$
\end{tabular}

Data represent Mean \pm Standard Error for five chicks per time

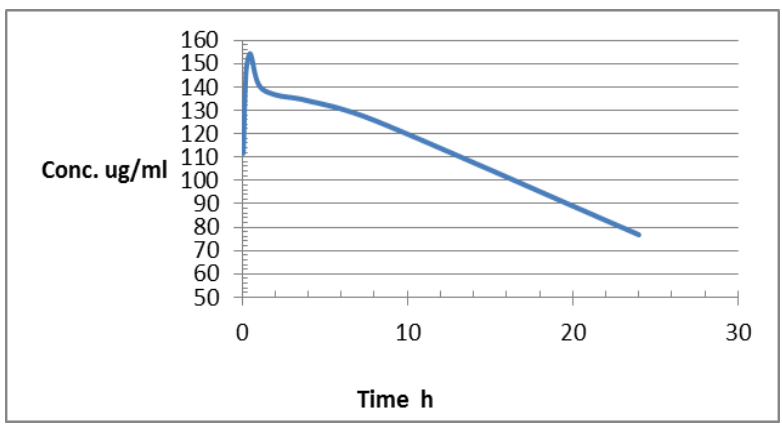

Figure 2 The flunixin concentration with time

\subsection{The pharmacokinetics parameters of flunixin meglumine}

The pharmacokinetic parameters of flunixin were measured in the plasma of chickens treated with flunixin at a dose of $18 \mathrm{mg} / \mathrm{kg}$ i.p. The maximum plasma concentration was $154.23 \mu \mathrm{g} / \mathrm{ml}$ during a period of 0.5 hours of treatment. The terminal elimination half-life was 31 hours, the terminal phase elimination rate constant was $0.021 \mathrm{~h}^{-1}$, the mean residence time was 45 $\mathrm{h}$, and the area under the curve from time 0 to infinity was $6733.27 \mu \mathrm{g} . \mathrm{h} / \mathrm{ml}$ (Table 2).

Table 2. Pharmacokinetic variables for flunixin meglumine when given in the peritoneum to healthy chicks at a dose of $18 \mathrm{mg} / \mathrm{kg}$ body weight

\begin{tabular}{cc}
\hline variables & values \\
& \\
\hline$T_{1 / 2}$ & $31 \mathrm{~h}$ \\
\hline $\mathrm{K}_{e}$ & $0.021 \mathrm{~h}^{-1}$ \\
\hline$C_{\max }$ & $154,23 \mu \mathrm{g} / \mathrm{ml}$ \\
\hline$T_{\max }$ & $0.5 \mathrm{~h}$ \\
\hline $\mathrm{MRT}$ & $45 \mathrm{~h}$ \\
\hline $\mathrm{AUC}_{0-\infty}$ & $6733.27 \mu \mathrm{g} . \mathrm{h} / \mathrm{ml}$ \\
\hline
\end{tabular}

$T_{1 / 2}=$ Terminal Elimination Half-Life, $\mathrm{K}_{\mathrm{e}}=$ Terminal Phase Elimination Rate Constant, $C_{\max }=$ Maximum plasma concentration, $T_{\max }=$ Time to Maximum Plasma Concentration, MRT $=$ Mean Residence Time, AUC ${ }_{0-\infty}=$ Area Under the Curve from time 0 to infinity.

\section{DISCUSSION}

The use of ELISA test to measure the concentration of flunixin in the plasma of chicks confirmed the presence of flunixin after treatment with a dose $(18 \mathrm{mg} / \mathrm{kg}$, i.p), and its rapid absorption and access to the blood circulation during the first minutes after injection. The highest concentration was reached in 30 minutes, which is consistent with giving flunixin to goats at a dose of $2.2 \mathrm{mg} / \mathrm{kg}$ intramuscularly and highest concentration was observed after 30 minutes of the treatment[6]. In another study, when flunixin was administered to Norwegian goats at a dose of $2.2 \mathrm{mg} / \mathrm{kg}$ intramuscularly, the highest concentration was observed after 22 minutes of treatment[7]. It was observed that the mice treated with a dose of $2 \mathrm{mg} / \mathrm{kg}$ subcutaneously had the highest concentration after 17 minutes of treatment[8]. Also, in pigs treated with a dose of 2.2 $\mathrm{mg} / \mathrm{kg}$ intramuscularly, the highest concentration was observed one hour after treatment[9]. In horses, flunixin is rapidly absorbed orally with a mean bioavailability of $80 \%$, the highest concentration after 30 minutes and an effective period extending beyond 30 hours, and flunixin is highly bound to plasma proteins (99\% cattle, 
92\% dogs, $87 \%$ horses)[10]. Through the results of our study and previous studies, it becomes clear to us the fast absorption of flunixin in different routes of administration and it is attainment the highest concentration within a short period of time, and thus the haste of it is action as a pain reliever.

Kleinhenz et al. observed when flunixin was administered intravenously to 2-month and 8-month-old calves that clearance from plasma was slower in 2month-old in compare with 8-month-old calves, resulting in an increase in the area under the curve, elimination half-life, and mean residence time, The researcher conclude to extend the time period between one dose and another at young ages of animals[11]. So the age has an important role in pharmacokinetic parameters, and this opinion should be taken into account when comparing chicks and adult chickens.

From the results of our study, when flunixin was administered at a dose of $18 \mathrm{mg} / \mathrm{kg}$ i.p., the elimination rate constant was $\left(0.021 \mathrm{~h}^{-1}\right)$, the elimination half-life was (31 hours), the mean residence time was(45 hours), the time to maximum plasma concentration was $(0.5$ hours) and the maximum plasma concentration was $(154,23 \mu \mathrm{g} / \mathrm{ml})$. Compared to other studies; flunixin at a dose of $5 \mathrm{mg} / \mathrm{kg}$ orally in adult chickens, the elimination rate constant was $\left(0.114 \mathrm{~h}^{-1}\right)$, the elimination half-life was (6.1 hours), the mean residence time was (9.1 hours), the time to maximum plasma concentration was (1.5 hours) and the maximum plasma concentration was $(24.5 \mu \mathrm{g} / \mathrm{ml})[12]$. And in another study flunixin at a dose of $1.1 \mathrm{mg} / \mathrm{kg}$ intravenously in adult chickens, where the elimination rate constant was $\left(0.009 \mathrm{~h}^{-1}\right)$, the elimination half-life was(5.52 hours) and the mean residence time was (6.66 hours)[13]. These differences in pharmacokinetic parameters may be due to the differences in the dose, age, and route of administration. The elimination half-life of flunixin in horses $\approx 1.6-4.2$ hours, dogs 3.7 hours and cattle 3.1-8.1 hours, flunixin can be detected in the urine of horses for at least 48 hours after treatment[10]. The elimination half-life of flunixin in camels treated with flunixin at a dose of 1.1 $\mathrm{mg} / \mathrm{kg}$ and $2.2 \mathrm{mg} / \mathrm{kg}$ intravenously was 3.76 and 4.08 hours, respectively[14]. Flunixin is characterized by its high availability in tissues, and this high prevalence explains the long half-life of flunixin[15]. Also, the excretion of flunixin in chickens is slower than that of camels, horses, sheep, cattle and dogs[16].

From the results of our study, we noticed the haste of drug absorption and the length of the excretion period, which is evident through the concentration curve with time, as the elimination half-life was ( 31 hours), and this effect may be attributed to the high dose of the drug obtained from our previous study[4] and thus the increase in the effect of flunixin on the kidneys.

Non-steroidal anti-inflammatory drugs reduce the glomerular filtration rate by inhibiting the synthesis of prostaglandins[17]. The kidneys are highly active in the synthesis and metabolism of prostaglandins, and prostaglandins have an important role in many vital processes in the kidneys, including automatic regulation of renal blood flow, glomerular filtration, control of renin release, and transport of ions and water in the renal tubules. It is not surprising that the inhibition of prostaglandin synthesis Leads to a disturbance in the physiological process of the kidneys, leading to kidney dysfunction[18]. Also, the renal tubules actively transport drug molecules from the plasma to the tubular lumen, and it has an important role in the excretion and reabsorption of drug molecules in the kidneys and can affect the amount of drug excreted and reabsorbed in the renal tubules[19]. The excretion of flunixin through the kidneys decreases in the presence of a disturbance in the function of the kidneys[20]. Thus, it can be concluded that the effect of flunixin on the kidney has an important role in the long half-life and clearance from the body.

Also, the rate of drug excretion which has a highly binding to protein is weak, the reason is that the glomerular filtration in the kidneys and hepatic metabolism are limited only to the free molecule of drug in the plasma[21]. Flunixin is a fat-soluble drug that spreads widely in the body, and it has been shown binds strongly to plasma proteins[22].

\section{CONCLUSION}

We conclude from the study the long elimination halflife of flunixin in addition to the poor clearance from the animal body, which is reflected in the long period of its analgesic, anti-inflammatory and antipyretic effects.

\section{AUTHORS' CONTRIBUTIONS}

The two researchers contributed equally to the completion of the research.

\section{ACKNOWLEDGMENTS}

Thanks to the College of Veterinary Medicine for the unlimited support to complete the research, which is part of the master's study for the first author.

\section{REFERENCES}

[1] A. Naser, Y. Albadrany, K.A. Shaaban, Methods of Pain Assessment in Chicks as a Model, Egyptian Journal of Veterinary Sciences52(2) 2021 pp. 241249.DOI:https://dx.doi.org/10.21608/ejvs.2021.6460 5.1219

[2] K.L. Machin, Avian analgesia. In: Seminars in Avian and Exotic Pet Medicine, Elsevier; 2005 pp. 236-242.

DOI:https://doi.org/10.1053/j.saep.2005.09.004 
[3] F. Hassan, S. Altaf, M. Ijaz, M. Tahir, A Review on Flunixin Meglumine. International Journal of Medicine Research 1(2) 2016 pp. 136-138. DOI;https://doi.org/10.1016/0262-1746(87)90069-2

[4] Z. Alhumdany, Y. Albadrany, The Safety Profile of Flunixin and its Pharmacological Effects in Chicks. Egyptian Journal of Veterinary Sciences 52(2) 2021 pp. 229-236.DOI: https://dx.doi.org/10.21608/ejvs.2021.65150.1220

[5] Y., Zhang, M. Huo, J. Zhou, S. Xie, PKSolver: An add-in program for pharmacokinetic and pharmacodynamic data analysis in Microsoft Excel. Computer methods and programs in biomedicine 99(3) $2010 \quad$ pp. 306-314. DOI:https://doi.org/10.1016/j.cmpb.2010.01.007

[6] C.M. Bublitz, D.A. Mzyk, T. Mays, V.R. Fajt, T Hairgrove., R.E. Baynes, Comparative plasma and urine concentrations of flunixin and meloxicam in goats. Small Ruminant Research (174) 2019 pp. 4046.

DOI:https://doi.org/10.1016/j.smallrumres.2019.01.0 13

[7] K. Königsson, K. Törneke, I.V. Engeland, K. Odensvik, H. Kindahl, Pharmacokinetics and pharmacodynamic effects of flunixin after intravenous, intramuscular and oral administration to dairy goats. Acta Veterinaria Scandinavica44(4) 2003 pp. 1-7.DOI: https://doi.org/10.1186/17510147-44-153

[8] T. Ogino, T. Arai, Pharmacokinetic interactions of flunixin meglumine and enrofloxacin in ICR mice. Experimental animals 56 (2) 2007 pp. 79-84. DOI:https://doi.org/10.1538/expanim.56.79

[9] J.L. Bates, L.A. Karriker, S.M Rajewski., Z. Lin, R. Gehring, M. Li, A study to assess the correlation between plasma, oral fluid and urine concentrations of flunixin meglumine with the tissue residue depletion profile in finishing-age swine. BMC veterinary research 16(1) 2020 pp. 1-13. DOI:https://doi.org/10.1186/s12917-020-02429-w

[10] K. Cavanagh, Plumb's Veterinary Drug Handbook. Pocket-7th edition. The Canadian Veterinary Journal 53(12) 2012 p. 539.

[11] M.D. Kleinhenz, N.K. Van Engen, P.J. Gorden, J.S. Smith, B. KuKanich, S.M. Rajewski, Effect of age on the pharmacokinetics and pharmacodynamics of flunixin meglumine following intravenous and transdermal administration to Holstein calves. American journal of veterinary research 79(5) 2018 pp. 568575.DOI: https://doi.org/10.2460/ajvr.79.5.568

[12] J.M.B. Musser, Pharmacokinetics of flunixin in chickens after oral and intravenous administration. Journal of veterinary pharmacology and therapeutics 33(3) 2010 pp. 312-314. DOI:https://doi.org/10.1111/j.1365-

2885.2009.01132.x

[13]K.Baert,P.DeBacker,Comparative pharmacokinetics of three non-steroidal anti-inflammatory drugs in five bird species. Comparative Biochemistry and Physiology Part C: Toxicology \& Pharmacology134(1) 2003 pp. 25-33. DOI:https://doi.org/10.1016/S15320456(02)00184-9

[14] I.A. Wasfi, N.S. Boni, A.A. Abdel Hadi, M., Elghazali,O.Zorob,N.A.Alkatheeri,Pharmacokineti cs, metabolism and urinary detection time of flunixin after intravenous administration in camels. Journal of Veterinary Pharmacology and Therapeutics 21(3)1998 pp. 203-208. DOI:https://doi.org/10.1046/j.13652885.1998.00122.x

[15] E. Nixon, G.W. Almond, R.E. Baynes, K.M. Messenger, Comparative Plasma and Interstitial Fluid Pharmacokinetics of Meloxicam, Flunixin, and Ketoprofen in Neonatal Piglets. Frontiers in veterinary science (7)2020 p. 82 DOI:https://doi.org/10.3389/fvets.2020.00082

[16] K. Baert, P. De Backer, Disposition of sodium salicylate, flunixin and meloxicam after intravenous administration in broiler chickens. Journal of veterinary pharmacology and therapeutics 25(6) 2002 pp. 449-453. DOI:https://doi.org/10.1046/j.13652885.2002.00441.x

[17] W.H. Hörl, Nonsteroidal anti-inflammatory drugs and the kidney. Pharmaceuticals 3(7) 2010 pp. 2291-2321.DOI: https://doi.org/10.3390/ph3072291

[18] T. Yasmeen, G.S. Qureshi, S. Perveen, Adverse effects of Diclofenac sodium on renal parenchyma of adult albino rats. Journal of the Pakistan Medical Association 57(7) 2007 pp. 349-351. PMID: 17867257.

[19] J. Yin, J. Wang, Renal drug transporters and their significance in drug-drug interactions. Acta Pharmaceutica Sinica B 6(5) 2016 pp. 363-373. DOI:https://doi.org/10.1016/j.apsb.2016.07.013

[20] Y.H. Hwang, H.I. Yun, Effects of acute hepatic and renal failure on pharmacokinetics of flunixin meglumine in rats. Experimental animals 60(2) 2011pp.187-191.

DOI:https://doi.org/10.1538/expanim.60.187

[21] Y. Miyazaki, Y. Horii, N. Ikenagi, M. Shimoda, E. Kokue, Possible active transport mechanism in pharmacokinetics of flunixin-meglumin in rabbits. Journal of Veterinary Medical Science 63(8) 2001 
pp.885-888.DOI:

https://doi.org/10.1292/jvms.63.885

[22] E. Nixon, T.P. Mays, P.A. Routh, J.L. Yeatts, V.R.

Fajt, T. Hairgrove, Plasma, urine and tissue concentrations of Flunixin and Meloxicam in Pigs. BMC Veterinary Research 16(1) 2020 pp. 1-10.

DOI:https://doi.org/10.1186/s12917-020-02556-4 